\title{
Editorial
}

\section{Zika Virus: What Have We Learned?}

\author{
Marco Aurélio Palazzi Sáfadi, MD, PhD ${ }^{1}$ \\ ${ }^{1}$ Division of Pediatric Infectious Diseases, Department of Pediatrics, \\ Santa Casa de São Paulo School of Medical Sciences, São Paulo, Brazil \\ Am J Perinatol 2016;33:1029-1031.
}

Zika virus (ZIKV) is an emerging arthropod-borne, enveloped RNA virus of the Flaviviridae family, which belongs to the genus Flavivirus, related to dengue, yellow fever, Japanese encephalitis, and West Nile viruses. Two major lineages, African and Asian, have been identified through phylogenetic analyses. ${ }^{1}$ ZIKV is transmitted to humans primarily by Aedes aegypti mosquitoes (and less commonly by other Aedes species, such as Aedes polynesiensis, Aedes hensilli, and Aedes albopictus), the same vector that can transmit dengue, chikungunya, and yellow fever viruses. ${ }^{2}$ Additional modes of transmission have been identified, including perinatal, in utero, sexual (ZIKV can be transmitted by a man to his sex partners), blood transfusion, and laboratory exposure. ${ }^{3}$ Although ZIKV RNA has been detected in breast milk, transmission through breastfeeding has not yet been demonstrated, reinforcing the current recommendations that mothers with ZIKV infection should maintain breastfeeding to their infants. ${ }^{3}$

For 60 years, after it was first isolated from a rhesus monkey in a forest in Uganda in 1947, ZIKV has been only associated with sporadic cases in humans in Africa and Asia. However, since 2007 when the first outbreak of ZIKV outside Africa and Asia was reported in the Federated States of Micronesia (Yap), it has been identified in subsequent outbreaks in Southeast Asia and the Western Pacific. ${ }^{4,5}$ In May 2015, the Ministry of Health of Brazil confirmed autochthonous transmission of ZIKV associated with an outbreak of "dengue-like syndrome" cases in northeastern Brazil. ${ }^{6}$ The ZIKV outbreak continued to evolve, spreading geographically very rapidly in the Americas. As of June 8, 2016, 60 countries and territories report continuing mosquito-borne transmission, of which 46 countries (from the Americas, Africa, Southeast Asia, and Western Pacific regions) have been experiencing a first outbreak of ZIKV since 2015, with no previous evidence of circulation, and with ongoing transmission by mosquitos (-Fig. 1). ${ }^{7}$

ZIKV diagnosis is primarily based on the detection of ZIKV RNA by real-time reverse transcriptase-polymerase chain reaction in serum and/or urine during the 1 st week after onset of symptoms. However, since viremia decreases and disappears after the 1 st week of illness, a negative test result from serum collected more than 5 to 7 days after symptom onset does not exclude infection definitively. Recent data suggest that in urine ZIKV RNA can be detected longer, at least 2 weeks after onset of symptoms. ${ }^{8}$

ZIKV-specific IgM and neutralizing antibodies can be detected by enzyme-linked immunosorbent assay and immunofluorescence assay in serum specimens toward the end of the 1 st week of illness and typically persist for approximately 2 to 12 weeks. IgG antibodies develop within days after IgM and can be detected for months to years. However, false-positive results due to cross-reaction with related flaviviruses (e.g., dengue and yellow fever viruses) are commonly observed. Positive results in primary flavivirus infections should be confirmed with a fourfold increase in the titer of neutralizing antibodies to the ZIKV with plaque reduction neutralization test. In endemic areas, where a great proportion of the population is likely to have been previously infected with other flaviviruses or vaccinated against a related flavivirus (i.e., secondary flavivirus infection), neutralizing antibodies might still yield cross-reactive results in these individuals. $^{8}$

It is estimated that approximately $80 \%$ of persons infected with ZIKV are asymptomatic. When symptomatic, the infection is considered to be associated with a mild, self-limited disease, lasting a few days and characterized by low fever, a pruritic rash, edema of extremities, headache, and myalgia. Less common manifestations include gastrointestinal symptoms, retro-orbital pain, and lymphadenopathy. ${ }^{9}$ Severe presentations of the disease or deaths associated with ZIKV infection were not reported before the outbreaks in French Polynesia and Brazil.

However, the results of a recent study in a large series of patients from French Polynesia who developed GuillainBarré syndrome (GBS) following ZIKV infection, suggested that ZIKV should be included in the list of potential infectious pathogens that can trigger the development of GBS. ${ }^{10}$ In Brazil, hospital-based surveillance data revealed a significant increase in the number of GBS and other neurological and autoimmune complications (including myelitis and acute disseminated encephalomyelitis) reported during the recent outbreak in several states of the northeastern region. ${ }^{11,12}$ Furthermore, Colombia, Venezuela, and other countries from the Central America also reported an increase in the rates of GBS compared with previous years. ${ }^{13}$
Address for correspondence Marco Aurélio Palazzi Sáfadi, MD, $\mathrm{PhD}$, Alameda dos Indigenas, 228, ZIP 04059 060, São Paulo, Brazil (e-mail: masafadi@uol.com.br).
Copyright $\odot 2016$ by Thieme Medical Publishers, Inc., 333 Seventh Avenue, New York, NY 10001, USA.

Tel: +1(212) 584-4662.
DOI http://dx.doi.org/ 10.1055/s-0036-1586116. ISSN 0735-1631. 


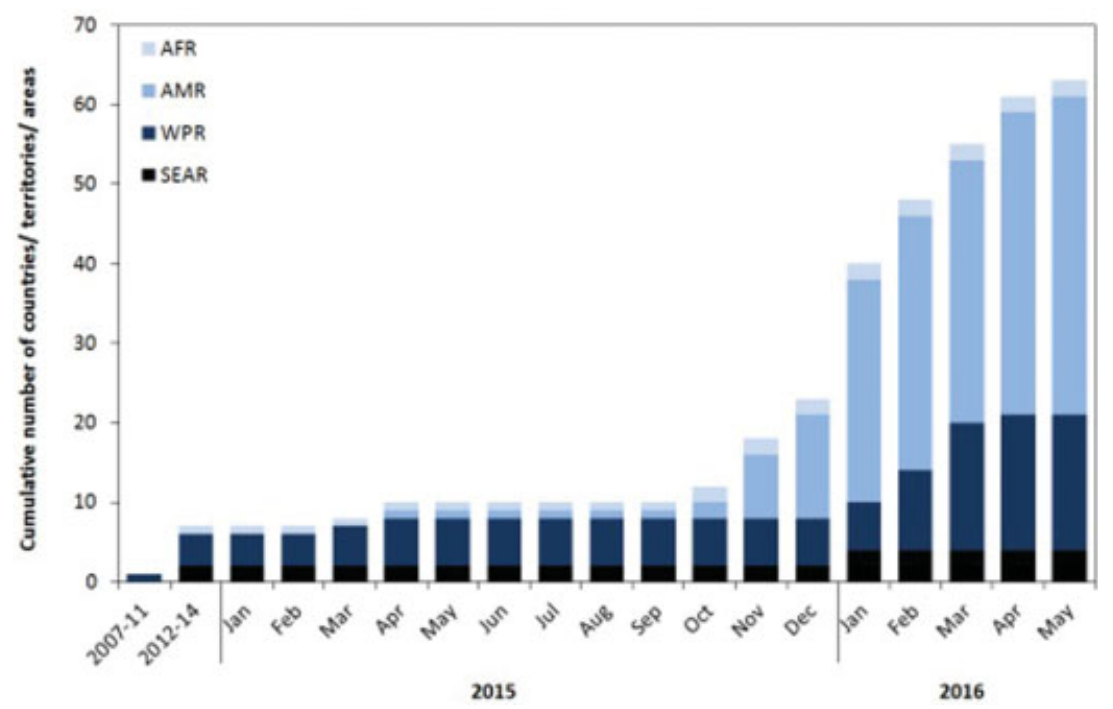

Fig. 1 The cumulative number of countries, territories, and areas by the World Health Organization region reporting mosquito-borne Zika virus transmission in years, 2007 to 2014, and monthly from January 1, 2015 to June 8, 2016. (Reprinted with permission from World Health Organization. ${ }^{7}$ )

The most striking finding during the ZIKV outbreak in Brazil, however, is the strong cumulative evidence that provided the basis to establish a link between ZIKV infection during pregnancy and fetal and placental abnormalities, including detection of virus genome by reverse transcriptase-polymerase chain reaction in amniotic fluid samples of women whose fetuses have been diagnosed with microcephaly, in placental tissues from early miscarriages and also in the blood and brain tissue of infants with congenital neurological anomalies, including microcephaly. The congenital neurological malformations were characterized predominantly by microcephaly (with significant cranium-facial disproportion) and cerebral calcifications, but lissencephaly with agenesis of the corpus callosum, pachygyria, hydrocephalus, and cerebellar dysplasia were also reported. ${ }^{14-18}$ The severity of the neurological alterations appears to be related to the period of gestation when the women are infected, that is, the earlier the infection during pregnancy, the more severe the neurological outcomes to the fetus. Arthrogryposis, microphthalmia, funduscopic alterations in the macular region, as well as optic nerve abnormalities were also described in infants with suspected congenital ZIKV infection. ${ }^{14-23}$

In a study performed in Rio de Janeiro, women infected during pregnancy with ZIKV were followed prospectively, and clinical and ultrasonographic data were collected. The authors found that fetal abnormalities were detected by Doppler ultrasonography in approximately $30 \%$ of the women. Also, important was the finding that neurological congenital abnormalities were seen in fetuses infected as late as 27 weeks of gestation. ${ }^{18}$

Since September 2015, in the northeastern region in Brazil, where ZIKV outbreaks peaked, a significant increase in the number of newborns with microcephaly, compared with the median rates reported in previous years to the local health authorities, was observed. As of June 4, 2016, 7,830 suspected cases of microcephaly and/or central nervous system malformation were reported in Brazil-of these 4,813 have been investigated further and among these cases, 1,551 had clinical and laboratory characteristics compatible with a congenital infection, and 224 had laboratory-confirmed ZIKV infection (-Fig. 2$)^{23}$

The true burden of the congenital disease associated with ZIKV is probably underestimated assuming that it is likely that a significant proportion of the affected newborns have subclinical manifestations at birth, without microcephaly, preventing these infants from being diagnosed by the current

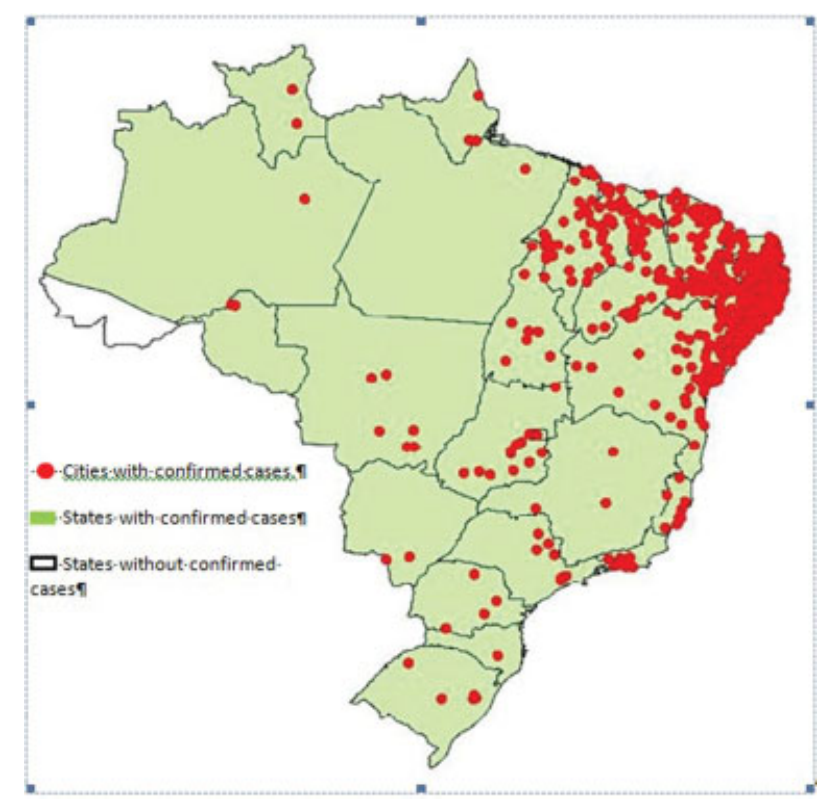

Fig. 2 The distribution of the confirmed cases of microcephaly and/or neonatal central nervous system alterations suggestive of congenital infections (Brazil, 2016). (Reprinted with permission from the Brazilian Ministry of Health. ${ }^{23}$ ) 
ascertainment methods, at least until later stages of childhood/adolescence when cognitive, developmental, and/or visual limitations can be detected. ${ }^{21}$

The unique characteristics of the ZIKV outbreak in Brazil, where the population was completely susceptible (naive) to the virus, affecting millions of persons from highly populated urban areas with established surveillance reporting system, are possible reasons explaining why the role of the ZIKV as a potential cause of congenital disease has only been recognized after circulating in Brazil. Interestingly, after the reports from Brazil, establishing that a causal relationship between ZIKV infection in pregnancy and microcephaly and other congenital malformations existed, a retrospective study performed in French Polynesia found an association between ZIKV and microcephaly. ${ }^{24}$

We currently do not have any available vaccines to prevent the disease or specific antiviral treatment for patients with ZIKV disease. One recent study showed that chloroquine exhibited antiviral activity against ZIKV in VERO, human brain microvascular endothelial, and neural stem cells. In this study, the authors were able to demonstrate that chloroquine reduced, in vitro, the number of ZIKV-infected cells, virus production, and cell death promoted by ZIKV infection without cytotoxic effects. ${ }^{25}$

The substantial number of infants born with the congenital Zika syndrome, presenting microcephaly and other neonatal neurological malformations that will be identified in the following months, not only in Brazil, but also in other countries, emphasizes the need to strengthen laboratory capacities and establish a quality surveillance system to detect these cases and confirm the association with ZIKV infection with well-designed epidemiological studies.

Finally, it is of paramount importance that health authorities in Brazil, as well as other affected countries in the region, intensify the efforts to control the Aedes aegypti mosquito, the same vector responsible for transmitting dengue, chikungunya, and yellow fever. In the short term, this is the most efficient measure to mitigate the huge public health burden of these infections.

\section{Conflict of Interest}

None.

\section{References}

1 Kuno G, Chang GJ, Tsuchiya KR, Karabatsos N, Cropp CB. Phylogeny of the genus Flavivirus. J Virol 1998;72(1):73-83

2 Gubler D, Kuno G, Markoff L. Flaviviruses. In: Knipe DM, Howley PM, eds. Fields Virology. Philadelphia, PA: Lippincott Williams \& Wilkins; 2007:1153-1252

3 Centers for Disease Control and Prevention. Zika virus. Available at: http://www.cdc.gov/zika/index.html. Accessed June 18, 2016

4 Duffy MR, Chen T-H, Hancock WT, et al. Zika virus outbreak on Yap Island, Federated States of Micronesia. N Engl J Med 2009;360(24): 2536-2543
5 Cao-Lormeau VM, Roche C, Teissier A, et al. Zika virus, French polynesia, South pacific, 2013. Emerg Infect Dis 2014;20(6):1085-1086

6 Campos GS, Bandeira AC, Sardi SI. Zika virus outbreak, Bahia, Brazil. Emerg Infect Dis 2015;21(10):1885-1886

7 World Health Organization. Zika situation report. Available at: http://www.who.int/emergencies/zika-virus/situation-report/9june-2016/en/. Accessed June 8, 2016

8 Centers for Disease Control and Prevention. Diagnostic testing. Available at: https://www.cdc.gov/zika/hc-providers/diagnostic. html. Accessed June 8, 2016

9 Ioos S, Mallet HP, Leparc Goffart I, Gauthier V, Cardoso T, Herida M. Current Zika virus epidemiology and recent epidemics. Med Mal Infect 2014;44(7):302-307

10 Cao-Lormeau V-M, Blake A, Mons S, et al. Guillain-Barré Syndrome outbreak associated with Zika virus infection in French Polynesia: a case-control study. Lancet 2016;387(10027):1531-1539

11 World Health Organization. Guillain-Barré syndrome-Brazil. Available at: http://www.who.int/csr/don/8-february-2016-gbsbrazil/en/. Accessed May 3, 2016

12 Mécharles S, Herrmann C, Poullain P, et al. Acute myelitis due to Zika virus infection. Lancet 2016;387(10026):1481

13 World Health Organization. Guillain-Barré syndrome-Colombia and Venezuela. Available at: http://www.who.int/csr/don/12-february-2016-gbs-colombia-venezuela/en/. Accessed May 3, 2016

14 Martines RB, Bhatnagar J, Keating MK, et al. Notes from the field: evidence of Zika virus infection in brain and placental tissues from two congenitally infected newborns and two fetal losses-Brazil, 2015. MMWR Morb Mortal Wkly Rep 2016;65(6):159-160

15 Schuler-Faccini L, Ribeiro EM, Feitosa IM, et al; Brazilian Medical Genetics Society-Zika Embryopathy Task Force. Possible association between Zika virus infection and microcephaly-Brazil, 2015. MMWR Morb Mortal Wkly Rep 2016;65(3):59-62

16 Mlakar J, Korva M, Tul N, et al. Zika virus associated with microcephaly. N Engl J Med 2016;374(10):951-958

17 Oliveira Melo AS, Malinger G, Ximenes R, Szejnfeld PO, Alves Sampaio S, Bispo de Filippis AM. Zika virus intrauterine infection causes fetal brain abnormality and microcephaly: tip of the iceberg? Ultrasound Obstet Gynecol 2016;47(1):6-7

18 Brasil P, Pereira JP Jr, Raja Gabaglia C, et al. Zika virus infection in pregnant women in Rio de Janeiro - Preliminary report. N Engl J Med 2016;16:742-752

19 Ventura CV, Maia M, Bravo-Filho V, Góis AL, Belfort R Jr. Zika virus in Brazil and macular atrophy in a child with microcephaly. Lancet 2016;387(10015):228

20 World Health Organization. Zika virus microcephaly and GuillainBarré syndrome situation. Available at: http://apps.who.int/iris/ bitstream/10665/204526/2/zikasitrep_4Mar2016_eng.pdf?ua=1. Accessed May 4, 2016

21 Marrs C, Olson G, Saade G, et al. Zika virus and pregnancy: a review of the literature and clinical considerations. Am J Perinatol 2016; 33(7):625-639

22 Rasmussen SA, Jamieson DJ, Honein MA, Petersen LR. Zika Virus and Birth Defects-Reviewing the Evidence for Causality. N Engl J Med 2016;374(20):1981-1987

23 Brazilian Ministry of Health. Boletim epidemiológico. Available at: http://combateaedes.saude.gov.br/images/boletins-epidemiologicos/informe_microcefalia_epidemiologico29.pdf. Accessed June 08, 2016

24 Cauchemez S, Besnard M, Bompard P, et al. Association between Zika virus and microcephaly in French Polynesia, 2013-15: a retrospective study. Lancet 2016;387(10033):2125-2132

25 Delvecchio R, Higa L, Pezzuto P, et al. Chloroquine inhibits Zika Virus infection in different cellular models. BioRxiv 2016 (e-pub ahead of print). doi: 10.1101/051268. 